\title{
Potent Trivalent Inhibitors of Thrombin through Hybridization of Salivary Sulfopeptides from Hematophagous Arthropods
}

Citation for published version (APA):

Agten, S. M., Watson, E. E., Ripoll-Rozada, J., Dowman, L. J., Wu, M. C. L., Alwis, I., Jackson, S. P., Pereira, P. J. B., \& Payne, R. J. (2021). Potent Trivalent Inhibitors of Thrombin through Hybridization of Salivary Sulfopeptides from Hematophagous Arthropods. Angewandte Chemie-International Edition, 60(10), 5348-5356. https://doi.org/10.1002/anie.202015127

Document status and date:

Published: 01/03/2021

DOI:

10.1002/anie.202015127

Document Version:

Publisher's PDF, also known as Version of record

\section{Document license:}

Taverne

Please check the document version of this publication:

- A submitted manuscript is the version of the article upon submission and before peer-review. There can be important differences between the submitted version and the official published version of record.

People interested in the research are advised to contact the author for the final version of the publication, or visit the DOI to the publisher's website.

- The final author version and the galley proof are versions of the publication after peer review.

- The final published version features the final layout of the paper including the volume, issue and page numbers.

Link to publication

\footnotetext{
General rights rights.

- You may freely distribute the URL identifying the publication in the public portal. please follow below link for the End User Agreement:

www.umlib.nl/taverne-license

Take down policy

If you believe that this document breaches copyright please contact us at:

repository@maastrichtuniversity.nl

providing details and we will investigate your claim.
}

Copyright and moral rights for the publications made accessible in the public portal are retained by the authors and/or other copyright owners and it is a condition of accessing publications that users recognise and abide by the legal requirements associated with these

- Users may download and print one copy of any publication from the public portal for the purpose of private study or research.

- You may not further distribute the material or use it for any profit-making activity or commercial gain

If the publication is distributed under the terms of Article $25 \mathrm{fa}$ of the Dutch Copyright Act, indicated by the "Taverne" license above, 


\title{
Potent Trivalent Inhibitors of Thrombin through Hybridization of Salivary Sulfopeptides from Hematophagous Arthropods
}

\author{
Stijn M. Agten, Emma E. Watson, Jorge Ripoll-Rozada, Luke J. Dowman, Mike C. L. Wu, \\ Imala Alwis, Shaun P. Jackson, Pedro José Barbosa Pereira, * and Richard J. Payne*
}

In memory of Chris Abell

\begin{abstract}
Blood feeding arthropods, such as leeches, ticks, flies and mosquitoes, provide a privileged source of peptidic anticoagulant molecules. These primarily operate through inhibition of the central coagulation protease thrombin by binding to the active site and either exosite I or exosite II. Herein, we describe the rational design of a novel class of trivalent thrombin inhibitors that simultaneously block both exosites as well as the active site. These engineered hybrids were synthesized using tandem diselenide-selenoester ligation $(D S L)$ and native chemical ligation (NCL) reactions in onepot. The most potent trivalent inhibitors possessed femtomolar inhibition constants against $\alpha$-thrombin and were selective over related coagulation proteases. A lead hybrid inhibitor possessed potent anticoagulant activity, blockade of both thrombin generation and platelet aggregation in vitro and efficacy in a murine thrombosis model at $1 \mathrm{mg} \mathrm{kg}^{-1}$. The rational engineering approach described here lays the foundation for the development of potent and selective inhibitors for a range of other enzymatic targets that possess multiple sites for the disruption of protein-protein interactions, in addition to an active site.
\end{abstract}

\section{Introduction}

Thrombin is the central enzyme within the blood coagulation pathway. The protease is responsible for triggering both procoagulant (fibrinogen cleavage to fibrin, coagulation factor activation and platelet activation $)^{[1,2]}$ and anticoagulant (thrombomodulin-dependent activation of protein $\mathrm{C})^{[3]}$ events. These activities of thrombin are orchestrated through the binding of its native substrates to one, or both, of the two positively charged exosites (exosite I and exosite II) on the thrombin surface. Both exosites of thrombin are essential for normal hemostatic activities, either through direct binding of substrates or through cofactor binding. Exosite I in particular is implicated in the binding of fibrinogen and activation of coagulation factors, whereas exosite II is involved in platelet interactions through glycoprotein Ib $\alpha$ (GPIb $\alpha$ ) and fibrinogen $\gamma^{\prime}$ chain binding, and antithrombotic mechanisms through heparin binding.

The crucial roles of thrombin in hemostasis have logically resulted in this protease being targeted for anticoagulant therapy. Thrombin inhibitors developed to date can be divided into two classes, active site and bivalent inhibitors, the latter operating through blockade of both exosite I and the active site. While active site inhibitors are typically small molecules, for example, clinically approved argatroban and dabigatran, known bivalent inhibitors tend to be natural polypeptide inhibitors (or analogues thereof) produced within the salivary glands of hematophagous organisms. Examples include the archetypal leech-derived molecule hirudin, ${ }^{[4]}$ variegin (Var) discovered from the salivary glands of the tropical bont tick, Amblyomma variegatum, ${ }^{[5,6]}$ and the anophelin (Ano) family of polypeptides produced by the infamous malaria vector, the Anopheles mosquito. ${ }^{[7-9]}$ Importantly, each of these insect-derived peptide-based inhibitors has been shown to be post-translationally sulfated at one or more specific tyrosine (Tyr) residues, with the modification(s) leading to enhancement in thrombin inhibitory activity by 1-3 orders-of-magnitude compared to the unmodified variants. Very recently, we uncovered the crucial role of this Tyr sulfation within a novel class of bivalent thrombin inhibitors that inhibit thrombin activity through a unique binding mode, by occupying both the catalytic site and exosite II. Examples include the tick-derived madanins (from Haemaphysalis longicornis), ${ }^{[10]}$ hyalomins (from Hyalomma marginatum rufipes) and andersonins (from Dermacentor andersoni) ${ }^{[11]}$ and the tsetse fly-derived thrombin inhibitor (TTI) (from
[*] Dr. S. M. Agten, Dr. E. E. Watson, Dr. L. J. Dowman, Prof. R. J. Payne School of Chemistry and ARC Centre of Excellence for Innovations in Peptide and Protein Science, The University of Sydney Sydney, NSW 2006 (Australia)

E-mail: richard.payne@sydney.edu.au

Dr. S. M. Agten

Department of Biochemistry, Cardiovascular Research Institute Maastricht (CARIM), Maastricht University Universiteitssingel 50, 6229 ER Maastricht (The Netherlands)

Dr. J. Ripoll-Rozada, Dr. P. J. B. Pereira

IBMC-Instituto de Biologia Molecular e Celular and Instituto de Investigação e Inovação em Saúde, Universidade do Porto 4200-135 Porto (Portugal)
E-mail: ppereira@ibmc.up.pt

Dr. M. C. L. Wu, I. Alwis, Prof. S. P. Jackson

Charles Perkins Centre, The University of Sydney

Sydney, NSW 2006 (Australia)

and

Heart Research Institute

Sydney, NSW 2042 (Australia)

(2) Supporting information and the ORCID identification number(s) for

(iD) the author(s) of this article can be found under: https://doi.org/10.1002/anie.202015127. 
Glossina morsitans morsitans). ${ }^{[12]}$ For each of these peptides, Tyr sulfation at two residues within their respective sequences was shown to significantly enhance thrombin inhibitory and anticoagulant activity, partially attributed to increased electrostatic affinity to the positively charged exosite II.

Having revealed the distinct binding modes of these bivalent sulfopeptide inhibitors, we envisaged that engineered trivalent thrombin inhibitors could be developed, capable of occupying all three key binding regions of the proteinase through the end-to-end hybridization of known exosite I and exosite II-targeting inhibitors. Herein, we describe the design of these novel trivalent inhibitors based on crystal structures of Var, TTI and Ano in complex with thrombin. These novel hybrid inhibitors were each assembled via peptide ligation chemistry, enabling the thrombin inhibitory, antiplatelet and anticoagulant activities to be assessed.

\section{Results and Discussion}

\section{Structure-Guided Engineering of Trivalent Thrombin Inhibitors}

Based on their mechanistically and spatially distinct thrombin binding modes and potent anticoagulant activities, we selected three inhibitors to serve as scaffolds from which the proposed trivalent hybrid inhibitors could be constructed. Specifically, we selected the exosite I-binding inhibitors, variegin (Var) ${ }^{[5,6]}$ and a fragment of anophelin (Ano), ${ }^{[7,8]}$ bearing a single sulfotyrosine residue, and the bivalent exosite II binder, TTI, ${ }^{[12,13]}$ possessing two sulfotyrosine residues. Using crystal structures of $\alpha$-thrombin complexed with either Var, Ano from A. albimanus or TTI, we proposed a series of hybrid inhibitors 1-5 designed to bind to the active site, while straddling both exosite I and exosite II of the protease. It was envisaged that the trivalent binding of these molecules would lead to enhanced inhibitory potency against thrombin compared to the individual bivalent inhibitors.

Structures of the various thrombin-inhibitor complexes were first superposed (RMSD $=0.3 \AA$ ) and overlapping residues of inhibitors were identified. Unsurprisingly, a high degree of overlap was present in active site binding regions of the inhibitors and this region was therefore used as the grafting point between the exosite binding domains (Figure 1). In the TTI-Var hybrids $\mathbf{1}-\mathbf{3}$, the TTI active site-binding region [TTI(28-31)] was maintained, owing to the more potent inhibitory activity of sulfated TTI $\left(K_{\mathrm{i}}=0.59 \pm\right.$ $0.05 \mathrm{pM})$ compared to sulfated $\operatorname{Var}\left(K_{\mathrm{i}}=3.8 \pm 0.6 \mathrm{pM}\right.$, see Supporting Information). As such, residues $\operatorname{Var}(1-11)$ and TTI residue L32 (which is cleaved by thrombin ${ }^{[12]}$ ) were omitted from the hybridized structure (Figure 1). In place of these omitted residues, three amino acid-based linkers were incorporated; L-alanine, $\mathrm{N}$-methylglycine (sarcosine) and 2 aminoisobutyric acid (Aib) to provide inhibitors $\mathbf{1}, \mathbf{2}$ and $\mathbf{3}$, respectively (Scheme 1). We hypothesized that the L-alanine residue would provide conformational flexibility while retaining hydrophobic interactions (present in the parent inhibitors) in $\mathbf{1}$, whereas the sarcosine and Aib linkers within $\mathbf{2}$ and $\mathbf{3}$ would lead to hybrids stable against thrombin cleavage due to their positioning at the $\mathrm{P} 1^{\prime}$ site. In the case of
TTI-Ano hybrids $\mathbf{4}$ and $\mathbf{5}$, the Ano residues responsible for inhibition of the active site $[\operatorname{Ano}(50-53)]$ were maintained, taking advantage of the intrinsic resistance to proteolytic cleavage of this inhibitor, with residues TTI(30-32) and Ano(54-61) omitted. It should be noted that the Ano Nterminal tail [Ano(1-30)], was not included in the target hybrid structures as this region negligibly contributes to thrombin inhibition. ${ }^{[7]}$ The linking strategy between exosite Iand II-binding regions of hybrid inhibitors $\mathbf{4}$ and $\mathbf{5}$ required an altered synthetic approach as a result of the unique reversed binding mode of the Ano component. ${ }^{[7,8]}$ For this reason, a 2,3-diaminopropanamide (Dap) linker was incorporated to enable bidirectional conjugation to the C-termini of both the TTI and Ano fragments. Both L- and D-configured Dap linkers were incorporated in the proposed constructs $\mathbf{4}$ and $\mathbf{5}$, respectively, to determine the chirality at the $\alpha$-center that would optimally position the active site, exosite I- and IIbinding entities of the hybrid inhibitors.

\section{Synthesis of TTI-Var Hybrid Inhibitors 1-3}

Having designed the three TTI-Var hybrid constructs $\mathbf{1}-\mathbf{3}$, we next turned to the ligation-based assembly of these target molecules. We proposed that each of the inhibitors could be generated via a one-pot ligation of the three fragments, employing sequential diselenide-selenoester ligation (DSL)deselenization and native chemical ligation (NCL)-desulfurization chemistry (Scheme 1). ${ }^{[14-17]}$ Each of the suitably functionalized fragments necessary for the proposed ligation-based assembly were prepared via modified Fmoc-SPPS methods (see Supporting Information for synthetic details). The target fragments included TTI(1-13) sulfopeptide selenoester 6, Var(15-32) sulfopeptide 7 and bifunctional diselenide dimer fragments $\mathbf{8}-\mathbf{1 0}$ bearing a C-terminal thioester and an N-terminal $\beta$-selenoaspartate $[(\beta-\mathrm{Se}) \mathrm{Asp}]^{[18]}$ moiety. These latter bifunctional fragments were comprised of TTI(14-31) and Var(12-14) fragments, connected through L-Ala, sarcosine or Aib amino acid linkers (Scheme 1). It should be noted that the sulfotyrosine residues within sulfopeptides fragments 6 and 7 were incorporated with neopentyl (nP) sulfate ester protection, enabling the acid labile sulfate esters to remain intact during Fmoc-SPPS and reversed-phase HPLC purification (see Supporting Information for synthetic details). ${ }^{[10,19-21]}$

Assembly of the target hybrids began with a DSL reaction between selenoester $\mathbf{6}$ and bifunctional fragments 8-10. Specifically, fragments were dissolved in $6 \mathrm{M} \mathrm{Gn} \cdot \mathrm{HCl}, 0.1 \mathrm{M}$ HEPES buffer with $10 \mathrm{vol} \%$ DMF at $\mathrm{pH}$ 6.1-6.3 at room temperature, with each of the reactions proceeding to completion within 20 minutes (as judged by direct LC-MS analysis of the reaction mixture). The reaction mixture was next subjected to extraction with hexanes to remove diphenyl diselenide (DPDS) generated during the ligation, which would otherwise interfere with the ensuing deselenization and desulfurization steps in the proposed reaction sequence. Following DPDS extraction, tris-2-carboxyethylphosphine (TCEP) was added directly to the reaction mixture and the $\mathrm{pH}$ was adjusted to 6.8 to effect rapid deselenization of the 


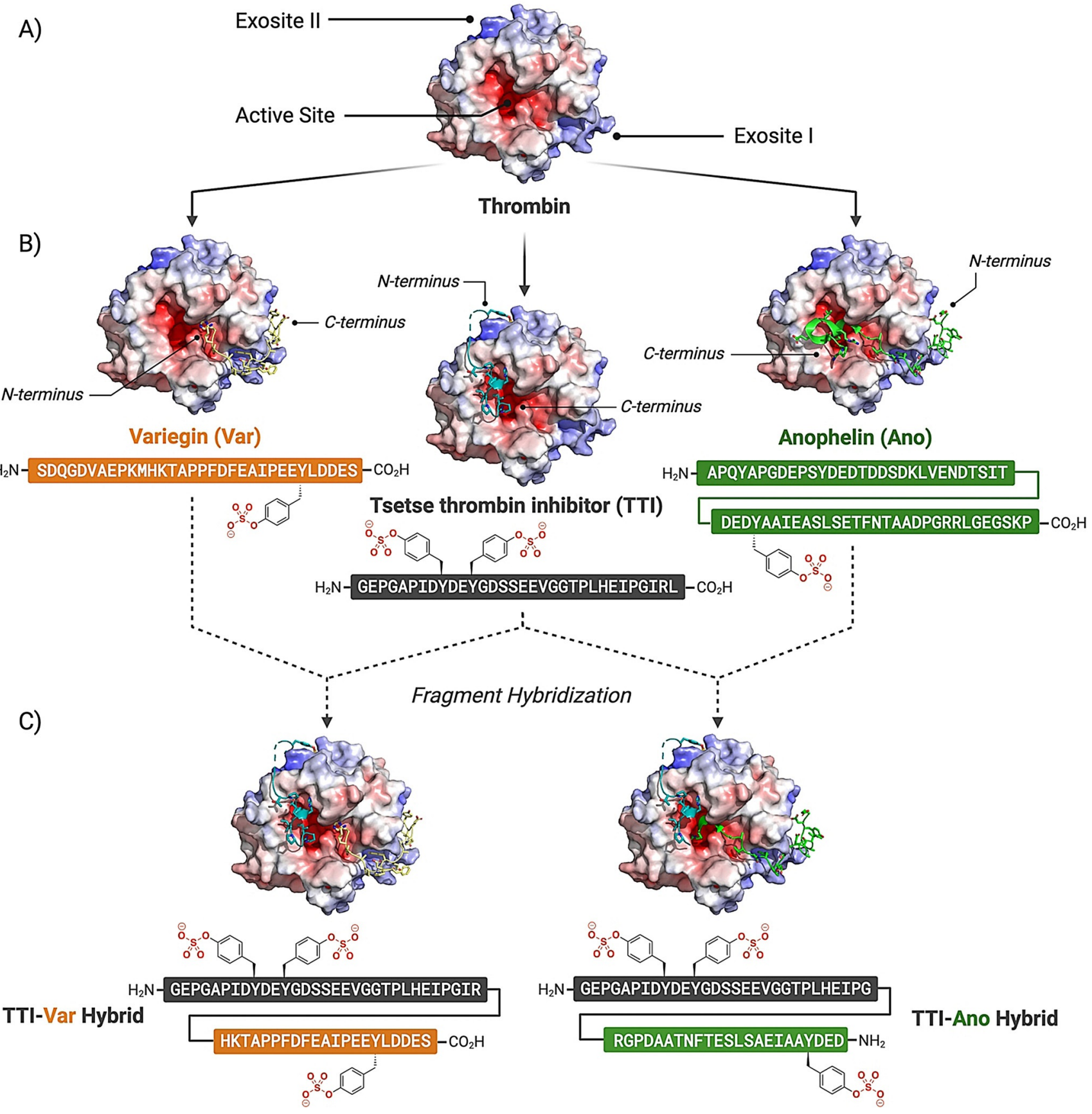

Figure 1. Structure-guided engineering of two classes of trivalent sulfopeptide thrombin inhibitors from three sulfated peptide inhibitors produced by hematophagous organisms. Displayed are the crystal structure of human thrombin (PDB: 3U69) showing the A) unliganded protein as a solid surface mapped with electrostatic potential surface (as calculated by APBS and contoured from +5 (blue) to -5 (red) $k_{\mathrm{B}} T \mathrm{e}^{-1}\left[k_{\mathrm{B}}=\mathrm{Boltzmann}^{\mathrm{s}}\right.$ constant, $T=$ temperature $(\mathrm{K}), \mathrm{e}=$ charge of an electron]) with the active site and positively charged exosites labeled, and $\mathrm{B}$ ) in complex with native bivalent sulfopeptide inhibitors; Variegin (Var; yellow) from Amblyomma variegatum (PDB: 3B23), Tsetse thrombin inhibitor (TTI; cyan) from Glossina morsitans morsitans (PDB: 6TKG) and anophelin (Ano; green) from Anopheles albimanus (PDB: 4E05). C) Overlay of TTI (G1-R31) and $\operatorname{Var}(\mathrm{H} 12-\mathrm{Y} 27)$ (left), and TTI (G1-G29) and Ano (E32-R53) (right) illustrating the potential for hybridization for the generation of engineered trivalent inhibitors.

now internally positioned ( $\beta$-Se)Asp to afford intermediates 11-13. Without purification, each of the reaction mixtures were directly subjected to subsequent NCL through addition of the $\operatorname{Var}(15-32)$ sulfopeptide fragment 7 and the exogenous thiol, 2,2,2-trifluoroethanethiol (TFET), at $\mathrm{pH} 7.1-7.3$ and $37^{\circ} \mathrm{C}^{[22]}$ Each of these ligations were complete within $16 \mathrm{~h}$ and led to concomitant nP sulfate ester deprotection (as judged by LC-MS analyses). From here, each of the reactions was subjected to in situ desulfurization by treatment with VA044, TCEP and reduced glutathione. ${ }^{[23]}$ Finally, purification by reversed-phase HPLC provided triply-sulfated hybrids 1-3 in $22-31 \%$ isolated yields over the DSL-deselenization-NCL- 

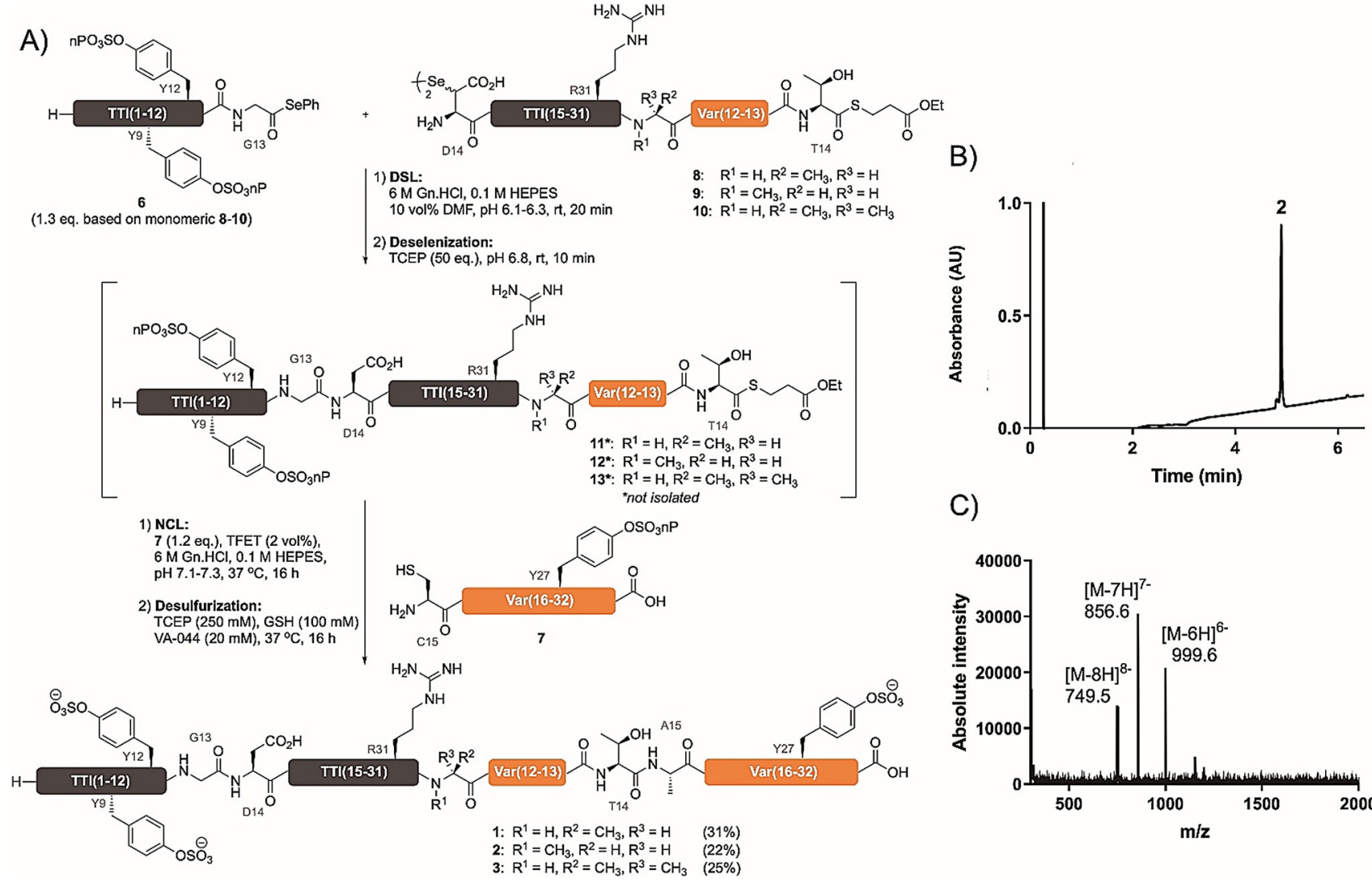

C)

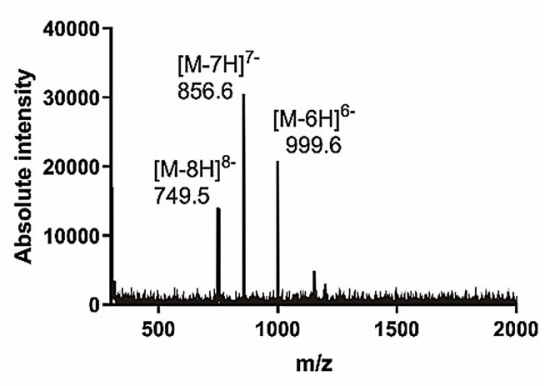

Scheme 1. A) Synthetic scheme for the assembly of TTI-Var sulfopeptide hybrids 1-3 using a three-component kinetically controlled ligation approach. B) Analytical HPLC (0\%B for $1 \mathrm{~min}$, then $0-50 \%$ B over $5 \mathrm{~min}, \lambda=214 \mathrm{~nm}$, Column: C18 XBridge BEH $5 \mu \mathrm{m} 2.1 \times 150 \mathrm{~mm}$ ) analysis of purified hybrid 2. C) MS (ESI-) analysis of purified hybrid 2.

desulfurization reaction sequence (see Scheme 1 for exemplar data for hybrid 2).

\section{Synthesis of TTI-Ano Hybrid Inhibitors 4 and 5}

Hybrid inhibitors $\mathbf{4}$ and $\mathbf{5}$ were also assembled via a onepot three component DSL-NCL assembly (Scheme 2). In contrast to 1-3, the reversed binding orientation of the Ano polypeptide (compared to Var) necessitated a design whereby both the TTI and Ano fragments were C-terminally fused to a Dap linker, leading to two N-termini (Scheme 2A). Synthesis of the central bifunctional diselenide dimer fragments 14 and 15 began from orthogonally protected Dap building blocks, $N \alpha-F m o c-N \beta$-Alloc-L-Dap (16a) and N $\alpha$-Fmoc-N $\beta$ Alloc-D-Dap (16b) (see Supporting Information for synthetic details), which were loaded to Rink amide resin. Staged bidirectional syntheses of $\mathbf{1 4}$ and $\mathbf{1 5}$ were carried out whereby Ano(49-53) was grown from the $\alpha$-amine of the anchored Dap residues, terminating in an $\mathrm{N}$-terminal Fmoc-protected thiazolidine (Thz) residue (to serve as a masked Cys). Final on-resin Fmoc-deprotection and reprotection of the free $\mathrm{N}$ terminal amine using an acid-labile Boc protection strategy, yielded the complete Ano fragment on resin. From here, Alloc deprotection of the side chain $\beta$-amine of the Dap residues and elongation of the TTI(14-29) fragment by FmocSPPS was carried out, with $(\beta-\mathrm{Se})$ Asp incorporated as the N- terminal residue. The other fragments necessary for the ligation-based assembly of the hybrids were Ano(31-48) sulfopeptide thioester fragment 17 (synthesized by FmocSPPS, see Supporting Information) and TTI(1-13) sulfopeptide selenoester 6 (common to hybrids 1-3). With the requisite fragments in hand, $\mathbf{1 4}$ and $\mathbf{1 5}$ were subjected to DSL with sulfopeptide selenoester 6 at $\mathrm{pH}$ 6.1-6.3 with $10 \mathrm{vol} \%$ DMF which proceeded to completion within 20 min (Scheme 2B). Extraction of DPDS with hexanes preceded adjustment of the $\mathrm{pH}$ of the crude reaction mixture to 4.0, after which the addition of TCEP (50 equiv) and methoxyamine $(200 \mathrm{mM})$ effected unmasking of the Thz to reveal Cys (ready for the subsequent NCL reaction). Importantly, these conditions also led to deselenization of the ( $\beta$ $\mathrm{Se}) \mathrm{Asp}$ residue and deprotection of the $\mathrm{nP}$ sulfate esters, affording intermediates $\mathbf{1 8}$ and 19. Without purification, Ano(31-48) thioester fragment $\mathbf{1 7}$ was added to the reaction mixture, the $\mathrm{pH}$ was adjusted to 7.1-7.2 and TFET added to activate the thioester for NCL. Following incubation of the mixture at $37^{\circ} \mathrm{C}$ over $16 \mathrm{~h}$, the ligation had reached completion and was immediately subjected to VA-044- and TCEP-mediated radical desulfurization. Purification by reversed-phase HPLC provided the target inhibitors $\mathbf{4}$ and $\mathbf{5}$ in $17 \%$ and $12 \%$ yield, respectively, over the entire reaction sequence in excellent purity (Scheme 2C-F). 
A)

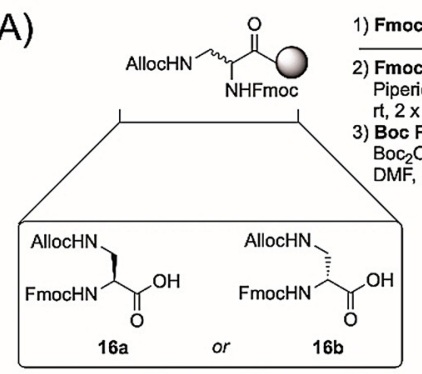

$$
\begin{aligned}
& \text { Fmoc-SPPS } \\
& \text { Fmoc Deprotection } \\
& \text { Piperidine (20 vol\%) in DMF } \\
& \mathrm{rt}, 2 \times 3 \text { min }
\end{aligned}
$$
Fmoc Deprotection
Piperidine $(20$ vol $\%)$ in DMF

(D)

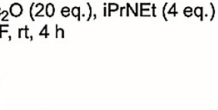

$\mathrm{F}, \mathrm{rt}, 4 \mathrm{~h}$
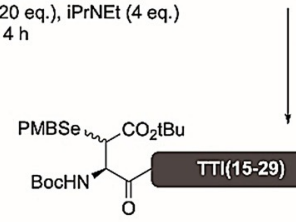

B)

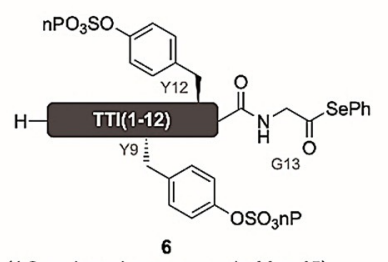

(1.2 eq. based on monomeric 14 or 15)

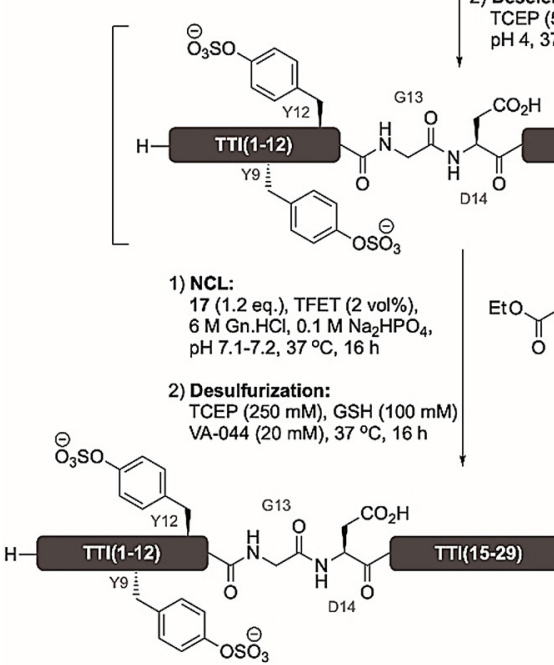
TCEeP (50 eq.), $\mathrm{MeONH}_{2}(100 \mathrm{mM})$,
$\mathrm{pH} 4,37^{\circ} \mathrm{C}, 8 \mathrm{~h}$

$$
\text { Til(15-29) }
$$
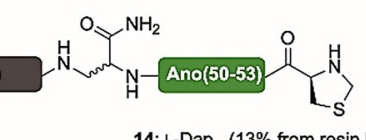

14: L-Dap (13\% from resin loading)
15: D-Dap ( $14 \%$ from resin loading) DSL:
$6 \mathrm{M} \mathrm{Gn} . \mathrm{HCl}, 0.1 \mathrm{M} \mathrm{Na}_{2} \mathrm{HPO}_{4}$ 10 vol\% DMF, pH 6.1-6.3, rt, $20 \mathrm{~min}$

$2 \mathrm{H}$ Tा1(15-29)<smiles>CCNC[C@H](NC)C(N)=O</smiles>
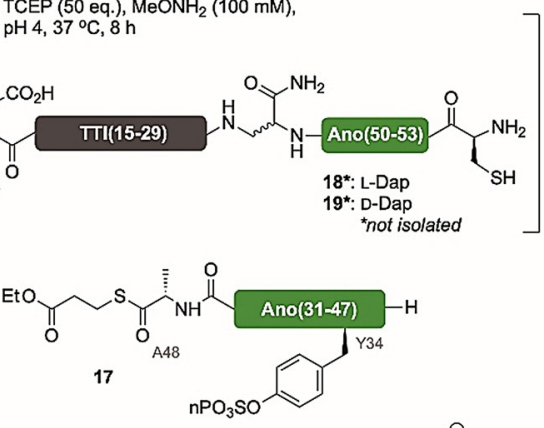

17

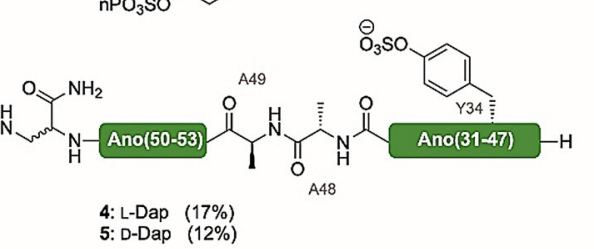

C)

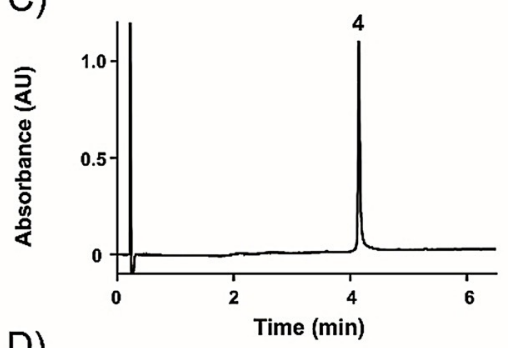

D)
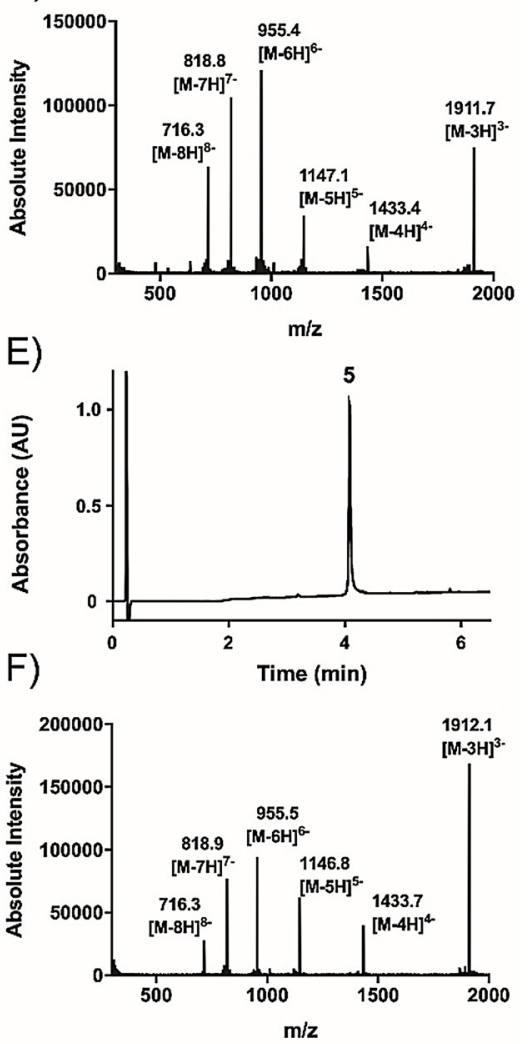

Scheme 2. A) Bi-directional solid-phase synthesis of 14 and 15 using a resin-immobilized and orthogonally-protected Dap residue. B) Threecomponent ligation-based assembly of TTI-Ano sulfopeptide hybrid inhibitors $\mathbf{4}$ and $\mathbf{5}$ using a tandem DSL-NCL strategy. C) Analytical HPLC (0\%B for $1 \mathrm{~min}$, then $0-70 \%$ B over $5 \mathrm{~min}, \lambda=214 \mathrm{~nm}$, Column: Waters XBridge (C-18) BEH $5 \mu \mathrm{m} 2.1 \times 150 \mathrm{~mm}$ ) analysis of purified hybrid 4 with D) MS (ESI-) spectrum of hybrid 4. E Analytical HPLC (0\%B for $1 \mathrm{~min}$, then $0-70 \% \mathrm{~B}$ over $5 \mathrm{~min}, \lambda=214 \mathrm{~nm}$, Column: Waters XBridge (C-18) BEH $5 \mu \mathrm{m} 2.1 \times 150 \mathrm{~mm}$ ) analysis of purified hybrid $\mathbf{5}$ with $\mathrm{F}$ ) MS (ESI-) spectrum of hybrid $\mathbf{5}$.

\section{In Vitro Thrombin Inhibition}

Following the successful synthesis of the novel sulfopeptide hybrids 1-5, we next evaluated their inhibitory activity against human $\alpha$-thrombin. Inhibitory activity was measured using a continuous assay with the chromogenic substrate TosGly-Pro-Arg- $p$-nitroanilide and the data fitted to a Morrison tight binding model to obtain $K_{\mathrm{i}}$ values for each of the trivalent inhibitors (Table 1). Gratifyingly, constructs from both hybrid series exhibited exquisitely potent thrombin inhibitory activities, with TTI-Var hybrid $2\left(K_{\mathrm{i}}=0.24 \pm\right.$ $0.08 \mathrm{pM})$ and TTI-Ano hybrids $4\left(K_{\mathrm{i}}=0.21 \pm 0.07 \mathrm{pM}\right)$ and $5\left(K_{\mathrm{i}}=0.02 \pm 0.03 \mathrm{pM}\right)$ displaying more potent inhibition
Table 1: Inhibitory constants $\left(K_{i}\right)$ for the synthetic trivalent inhibitors $\mathbf{1 - 5}$ against human $\alpha$ - and $\gamma$-thrombin. Inhibitory constants were obtained by fitting the activity data to a Morrison tight binding model. ${ }^{[25]}$

\begin{tabular}{lcc}
\hline Inhibitor & & $K_{\mathrm{i}}[\mathrm{pM}]$ \\
& $\alpha$-thrombin & $\gamma$-thrombin \\
\hline TTI-Var (1) & $80.2 \pm 4.8$ & N.D. \\
TTI-Var (2) & $0.24 \pm 0.08$ & $22.90 \pm 2.2$ \\
TTI-Var (3) & $580 \pm 31$ & N.D. \\
TTI-Ano (4) & $0.21 \pm 0.07$ & $3.49 \pm 0.34$ \\
TTI-Ano (5) & $0.02 \pm 0.03$ & $0.46 \pm 0.18$
\end{tabular}

N.D. = not determined. 
than the parent bivalent inhibitors (TTI: $K_{\mathrm{i}}=0.59 \pm$ $0.05 \mathrm{pM}^{[12]}$ Var: $K_{\mathrm{i}}=3.8 \pm 0.6 \mathrm{pM}, \quad$ Ano: $K_{\mathrm{i}}=7.7 \pm$ $1.1 \mathrm{pM}) .^{[8]}$ This enhanced inhibition was particularly pronounced in the case of TTI-Ano inhibitor $\mathbf{5}$ which displayed 30 -fold improved thrombin inhibitory activity compared to sulfated TTI and activity 385 -fold greater than singly sulfated Ano from A. albimanus (despite bearing only 23 of the 61 residues found in the native inhibitor). This clearly demonstrates that an additive effect to inhibitory potency is imparted through the fusion of these two inhibitors.

Notably, a dramatic effect on inhibitory activity was observed upon alteration of the linking amino acid in both series of trivalent inhibitors. Within the TTI-Var class of inhibitors, a three-orders-of-magnitude difference in thrombin inhibitory activity was observed between the least active inhibitor $3\left(K_{\mathrm{i}}=580 \pm 31 \mathrm{pM}\right)$, and the most potent $2\left(K_{\mathrm{i}}=\right.$ $0.24 \pm 0.08 \mathrm{pM})$, the only difference being the use of an Aib (3) vs. a sarcosine (2) linker; Ala-linked hybrid $\mathbf{1}\left(K_{\mathrm{i}}=80.2 \pm\right.$ $4.8 \mathrm{pM}$ ) displayed intermediate activity between $\mathbf{2}$ and $\mathbf{3}$. We hypothesized that the differences in thrombin inhibitory activity between the three hybrids was owing to variation in thrombin-mediated cleavage and/or direct steric effects within the linker region. As expected, hybrid inhibitor $\mathbf{1}$, bearing an Ala linker adjacent to the key P1 Arg residue, was cleaved rapidly by thrombin as judged by LC-MS analysis (see Supporting Information). Hybrid 3 with an Aib linker was also cleaved by thrombin, albeit slower than $\mathbf{1}$. In contrast, 2 bearing the $\mathrm{N}$-methylated sarcosine linker was completely resistant to thrombin cleavage. Given the enhanced potency of $\mathbf{1}$ (cleaved rapidly by thrombin) compared to $\mathbf{3}$, we rationalized that the gem-dimethyl $\alpha, \alpha$-substitution of Aib in 3 (likely located at the $\mathrm{P}^{\prime}$ ' site), might lead to a disruption of the orientation of the P1 Arg residue of the inhibitor within the thrombin active site, leading to less than optimal occupation of the S1 selectivity pocket of the enzyme. Conversely, decreasing steric bulk at the $\mathrm{C} \alpha$ position of the linking amino acid with the Ala residue in $\mathbf{1}$ likely minimizes disruption to contacts between neighboring residues of the inhibitor and the active site region of thrombin, thus leading to more potent inhibition (as observed for $\mathbf{1}$ and 2). Differences in potency were also observed within the TTI-Ano series of trivalent inhibitors due to the Ca stereochemistry of the Dap linker. Specifically, an order of magnitude difference in thrombin inhibitory activity was observed between $\mathbf{5}$, bearing a D-Dap linker $\left(K_{\mathrm{i}}=0.02 \pm 0.03 \mathrm{pM}\right)$ and 4, containing an L-Dap linker $\left(K_{\mathrm{i}}=0.21 \pm 0.07 \mathrm{pM}\right)$, suggesting that the D-Dap linker favors an optimal orientation of the two inhibitor segments for binding the exosites of thrombin.

Having determined that $\mathbf{2}, \mathbf{4}$ and $\mathbf{5}$ exhibited sub-pM inhibitory activity against $\alpha$-thrombin, we next moved to assess these hybrids against $\gamma$-thrombin (Table 1 ). This isoform of thrombin contains a disrupted exosite I which allows for the contribution of exosite II binding to inhibitory activity to be delineated. ${ }^{[24]}$ While each of the hybrids retained potent activity against $\gamma$-thrombin, inhibitory constants were found to be roughly an order of magnitude higher compared to those measured against $\alpha$-thrombin $\left(\mathbf{2}: K_{\mathrm{i}}=22.9 \pm 2.20 \mathrm{pM}\right.$, 4: $K_{\mathrm{i}}=3.49 \pm 0.34 \mathrm{pM}$, and 5: $\left.K_{\mathrm{i}}=0.46 \pm 0.18 \mathrm{pM}\right)$. These data confirm a clear contribution of both exosite I and II binding to the inhibitory activity and validate the design of the trivalent hybrid molecules. Finally, we assessed the selectivity of $\mathbf{2 , 4}$ and $\mathbf{5}$ against a panel of proteases including FXa, FXIa, FXIIa and plasmin. Each of the hybrids displayed exquisite selectivity for thrombin over these structurally related enzymes (see Supporting Information for data).

\section{Inhibition of Thrombin Generation by Hybrids 1-5}

Following these experiments on isolated thrombin enzyme, we next investigated the effectiveness of hybrid inhibitors 1-5 at inhibiting thrombin generation in human plasma. To this end, we employed a calibrated automated thrombogram (CAT) assay, which utilizes a fluorescently labeled thrombin substrate to measure the thrombin concentration within plasma in real time. ${ }^{[26]}$ Apart from directly measuring the inhibition of substrate conversion by thrombin, this assay can also provide insight into the effects of this inhibition on positive feedback loops governed by thrombin's exosites, for example, activation of coagulation factors V, VIII and XI. From the CAT assay, lag time, representing the time it takes for thrombin generation to occur, and peak height, indicating the maximal concentration of thrombin formed, are among the most important parameters to evaluate potency (Figure 2). Thrombin generation was first measured in normal pool plasma following the addition of tissue factor (TF) and phospholipids as a trigger. It should be noted that a low concentration of TF ( $2 \mathrm{pM})$ was used which is known to initiate thrombin formation (maximum concentration of 100 $150 \mathrm{nM}$ ) through both the extrinsic and intrinsic pathway of coagulation. ${ }^{[27]}$ The hybrid inhibitors 1-5 each exhibited potent inhibition of thrombin generation, with TTI-Var hybrid $\mathbf{2}$ and TTI-Ano hybrids $\mathbf{4}$ and $\mathbf{5}$ demonstrating the most potent activity, consistent with the inhibitory constants measured against $\alpha$-thrombin (Table 1). TTI-Var hybrid 2 demonstrated the most potent activity in the series where thrombin generation could be completely blocked with just $20 \mathrm{nM}$ of the inhibitor; notably, significant knockdown of thrombin generation and increase in lag time was still observed with $<1 \mathrm{nM}$ (Figure $2 \mathrm{~A}$ ). TTI-Ano hybrids 4 and 5 were able to completely inhibit thrombin generation at $40 \mathrm{nM}$. Importantly, hybrids $\mathbf{2}, \mathbf{4}$ and 5 each exhibited significantly enhanced activity when compared to the individual bivalent inhibitors TTI, Var and Ano (see Supporting Information). Due to the more potent activity of TTI-Var hybrid $\mathbf{2}$ in this thrombin inhibition assay, coupled with the greater ease in synthesizing this molecule (compared to the bidirectional hybrids $\mathbf{4}$ and $\mathbf{5}$ ) we selected $\mathbf{2}$ as a lead for profiling in more sophisticated in vitro and in vivo assays.

\section{Probing the Effects of TTI-Var Hybrid 2 on Coagulation}

The extrinsic pathway of coagulation is inhibited by tissue factor pathway inhibitor (TFPI), which reversibly binds to FXa and subsequently inhibits the FVIIa-TF complex. ${ }^{[28]} \mathrm{We}$ hypothesized that the increased lag time observed upon addition of the hybrids (particularly striking for 2 ) may lead to 


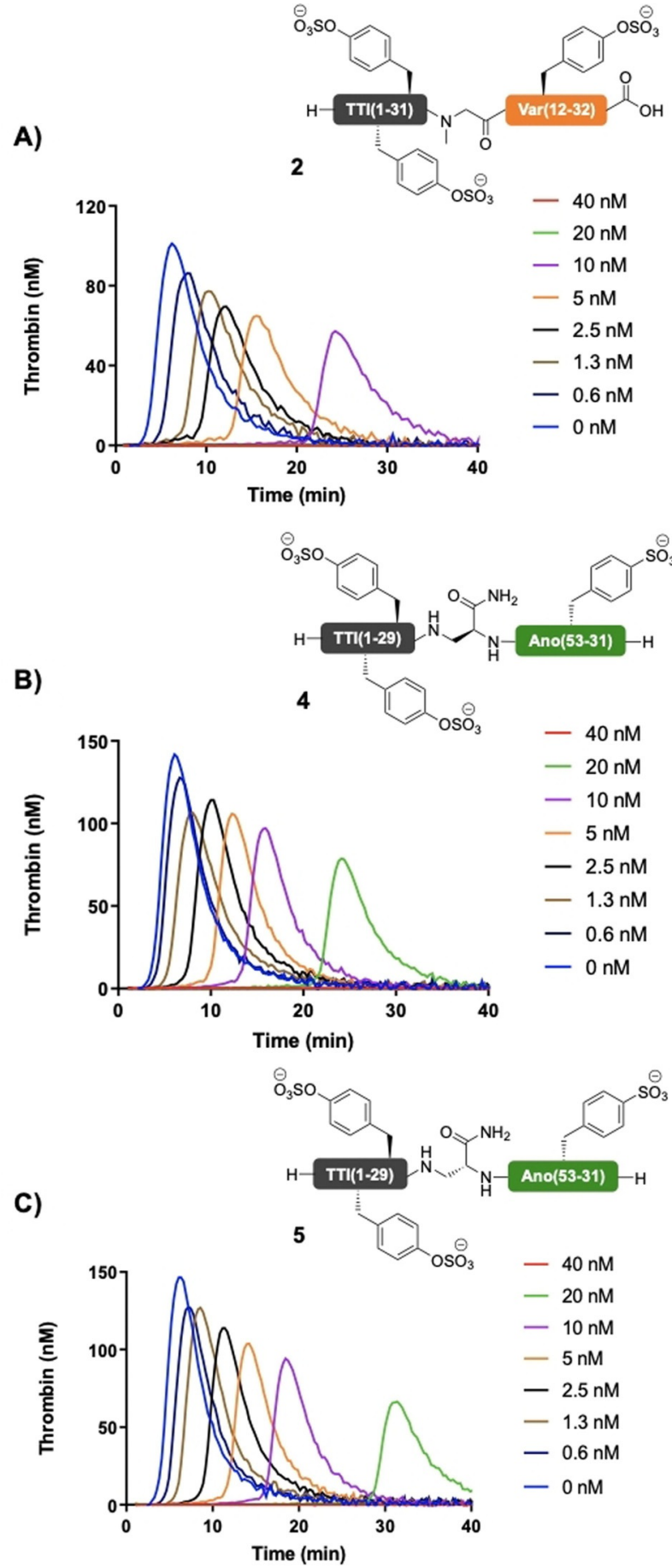

Figure 2. Thrombin generation in the presence of increasing concentrations (0-40 nM) of A) TTI-Var hybrid 2 and TTI-Ano hybrids B) 4 and C) $\mathbf{5}$ (see Supporting Information for thrombin generation data for hybrids $\mathbf{1}$ and $\mathbf{3}$ and sulfated variants of parent inhibitors TTI, Var and Ano).

an increased inhibitory function of TFPI. We therefore performed thrombin generation in the presence of $\mathbf{2}$ with and without anti-TFPI antibodies to eliminate any inhibitory contribution from TFPI (Figure $3 \mathrm{~A}$ and B). Both peak height and lag time were significantly modulated in the presence of the anti-TFPI cocktail, indicating that the inhibitory function
A)
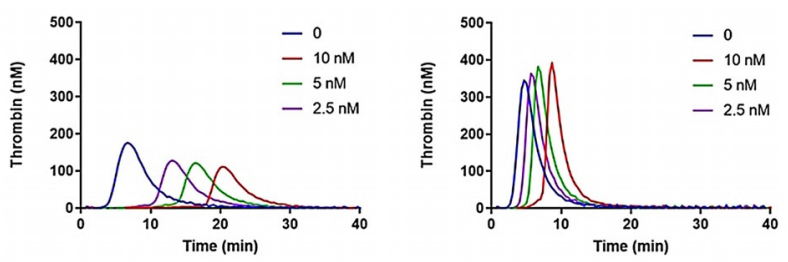

C)

D)
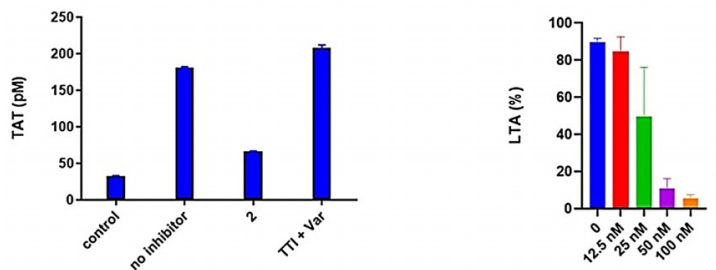

Figure 3. Effects of trivalent inhibitors on native inhibitors of coagulation and platelet aggregation. A) Thrombin generation in presence of 2 at concentrations of $0-10 \mathrm{nM}$ ). B) Thrombin generation in presence of 2 at concentrations of $0-10 \mathrm{nM}$ in the presence of an anti-TFPI antibody cocktail. C) Thrombin-Antithrombin (TAT) complex formation in thrombin-spiked $(250 \mathrm{pM})$ plasma in the presence of trivalent inhibitor $2(300 \mathrm{pM})$. D) Platelet activation triggered by thrombin $(50 \mathrm{nM})$ as determined by light transmission aggregometry in the presence of increasing concentrations of $\mathbf{2}$.

of TFPI is indeed amplified in presence of hybrid inhibitors. We also investigated how direct thrombin inhibition by antithrombin (AT) is influenced by $\mathbf{2}$. AT captures thrombin by covalent binding to its active site; this generates thrombinantithrombin (TAT) complexes which can be detected by ELISA (see Supplementary Information). Briefly, human defibrinated plasma was spiked with a known concentration of human $\alpha$-thrombin $(250 \mathrm{pM})$ and TAT levels were measured in the presence of $300 \mathrm{pM}$ of $\mathbf{2}$, compared to the absence of inhibitor or a mixture of the native bivalent inhibitors TTI and the exosite I-binding region of Var, from residues 15-32 at equal molarity to 2 (Figure 3C). Results showed approximately equivalent TAT levels in both the absence of inhibitor $\mathbf{2}$ and in presence of a combination of TTI and Var (Figure 3C). However, no AT-mediated thrombin inhibition was observed in the presence of trivalent inhibitor 2, corroborating the extremely high affinity with which this engineered hybrid inhibitor interacts with thrombin.

\section{Inhibition of Platelet Activation by TTI-Var Hybrid 2}

We next evaluated the effects of TTI-Var hybrid inhibitor 2 on platelet activation. Thrombin can activate platelets via exosite I-mediated cleavage of protease activated receptors (PARs) and binds via exosite II-mediated interactions to platelets through GPIb $\alpha{ }^{[29,30]}$ Previous studies have demonstrated that allosteric exosite II inhibition can lead to antiplatelet effects. ${ }^{[31]}$ We thus hypothesized that our inhibitors would also be capable of inhibiting platelet activation 
through high-affinity dual exosite binding. Platelet function was assessed using a light transmission aggregometry (LTA) assay, whereby washed platelets were incubated with increasing concentrations of $\mathbf{2}(12.5-100 \mathrm{nM})$ and subsequently activated by the addition of thrombin $(50 \mathrm{nM})$. These experiments clearly show that $\mathbf{2}$ exhibits potent inhibitory activity of platelet aggregation, with complete suppression of aggregation at concentrations $>50 \mathrm{nM}$ (Figure $3 \mathrm{D}$ ). Importantly, this result demonstrates the ability of our trivalent inhibitor to potently abrogate the pro-platelet functions of thrombin.

\section{In Vivo Antithrombotic Activity of TTI-Var Hybrid Inhibitor 2}

Having thoroughly profiled TTI-Var hybrid $\mathbf{2}$ in a suite of in vitro assays, we next sought to investigate the antithrombotic efficacy of the molecule in vivo. We chose to employ a localized needle injury model which leads to formation of thrombi at the site of injury under non-inhibitive conditions. ${ }^{[32]}$ Thrombus formation is driven dually by both platelet aggregation and fibrin formation, visualized by Dylight488 $\alpha$-GP1b $\beta$ and Alexa-647 $\alpha$-fibrin, respectively. Treatment with trivalent hybrid inhibitor $\mathbf{2}$ was compared to the clinically employed anticoagulant hirudin. Both inhibitors exhibited a statistically significant and equivalent reduction in thrombus volume at doses of $1 \mathrm{mg} \mathrm{kg}^{-1}$ (Figure $4 \mathrm{~A}$ ). Interestingly, 2 demonstrated a more consistent reduction in fibrin intensity from initial injury compared to hirudin (Figure 4B), potentially implicating a more rapid binding event (by way of dual exosite binding) of this inhibitor.
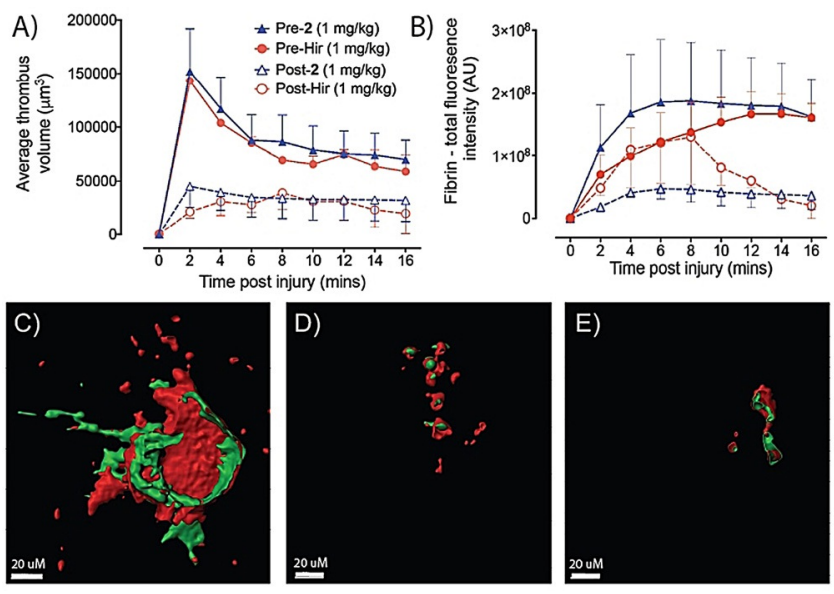

Figure 4. Antithrombotic effects of trivalent inhibitor 2 and hirudin in a murine needle injury thrombosis model. A) Time course of average thrombus volume. B) Time course of fibrin fluorescent intensity. C) Exemplar image of thrombus after needle injury without inhibitor. D) Exemplar image of thrombus after treatment with $1 \mathrm{mg} \mathrm{kg}^{-1}$ hirudin. E) Exemplar image of thrombus after treatment with $1 \mathrm{mg} \mathrm{kg}^{-1} \mathbf{2}$. NB: images represent a slice through the 3D thrombus, 15 min after needle injury, with fibrin indicated in green and platelets indicated in red. For all studies involved in using animals, male C57BL/6 mice aged approximately 5 weeks old $(20 \mathrm{~g})$ were used. These studies were approved by the University of Sydney Animal Ethics Committee (2017/ 1197) in accordance with the requirements of the Australian Code of Practice for the Care and Use of Animals for Scientific Purposes.

\section{Conclusion}

In summary, we have described two classes of engineered trivalent thrombin inhibitors, generated through the hybridization of bivalent sulfopeptide thrombin inhibitors produced in the salivary glands of a hematophagous fly (TTI), tick (Var) and mosquito (Ano). Crystallographic data of these naturallyoccurring inhibitors in complex with human $\alpha$-thrombin were leveraged to guide the engineering of TTI-Var 1-3 and TTIAno 4 and 5 hybrid inhibitors, designed to occupy the active site and both exosites I and II of the protease. Assembly of these hybridized inhibitors was successfully achieved through an efficient three-fragment, one-pot DSL-NCL tandem ligation strategy.

Engineered hybrids 2, 4 and 5 exhibited significantly improved inhibition of human $\alpha$-thrombin, compared to the naturally occurring bivalent inhibitors. With inhibitory constants in the femtomolar range, these represent some of the most potent protease inhibitors discovered to date. The reduced activity of hybrids $\mathbf{1}$ and $\mathbf{3}$ highlighted the importance of both the type and stereochemistry of the amino acid linker that connects the two exosite-directed halves of the trivalent inhibitors, threading through the active site cleft of the enzyme, with single amino acid changes resulting in a twothree orders of magnitude loss in thrombin inhibitory activity. Importantly, hybrid inhibitors $\mathbf{2 , 4}$ and $\mathbf{5}$ also showed potent inhibition of thrombin generation, with TTI-Var hybrid $\mathbf{2}$ able to completely inhibit thrombin generation at a concentration of $20 \mathrm{nM}$. Lead hybrid 2 was also assessed in more sophisticated assays that probed the effect of the molecule on coagulation feedback loops. Specifically, hybrid $\mathbf{2}$ was shown to potentiate TFPI-mediated inhibition of thrombin generation. Additionally, this hybrid was shown to entirely outcompete the action of the covalent natural thrombin inhibitor AT. Finally, TTI-Var hybrid $\mathbf{2}$ was assessed for in vivo efficacy in a murine thrombosis model. Gratifyingly, the engineered inhibitor was shown to significantly reduce thrombus volume by depletion of fibrin formation and platelet aggregation.

To our knowledge, this represents the first report of an engineered trivalent inhibitor of an exosite-containing protease. It is envisioned that this work will lay the foundation for structure-guided engineering of other hybrid biomolecules inspired by native peptidic inhibitors in the future. Furthermore, as emerging epidemiological trends demand further developments in the treatment of thrombogenic pathologies, we foresee such trivalent hybrid inhibitors-through their exquisite potency, anti-platelet effects and in vivo efficacysparking a renewed therapeutic interest in novel direct thrombin inhibitors. One potential application, outside of traditional thrombotic conditions where anticoagulants are used, would be for thrombotic complications associated with SARS-CoV-2 infection, from which a high number of patients present with venous or arterial thromboembolisms. ${ }^{[33]}$

\section{Acknowledgements}

The authors would like to acknowledge funding from the National Health and Medical Research Council Investigator 
Grant Scheme APP1174941 (to R.J.P.) and the CARIM HSBAFTA postdoctoral fellowship Scheme (to S.M.A.). This work was funded in part by national funds through Fundação para a Ciência e a Tecnologia (Portugal) in the form of Contract DL 57/2016/CP1355/CT0011 (to J.R.-R.). The authors also thank Dr Nicholas Proschogo and Dr Cody Szczepina for their assistance with mass spectrometry and HPLC, respectively.

\section{Conflict of interest}

The authors declare no conflict of interest.

Keywords: anticoagulant · peptide engineering · peptide ligation $\cdot$ protein synthesis . Thrombin

[1] J. A. Huntington, J. Thromb. Haemostasis 2005, 3, 1861-1872.

[2] M. T. Stubbs, W. Bode, Thromb. Res. 1993, 69, 1-58.

[3] J. Ye, L. W. Liu, C. T. Esmon, A. E. Johnson, J. Biol. Chem. 1992, 267, 11023-11028.

[4] T. J. Rydel, K. G. Ravichandran, A. Tulinsky, W. Bode, R. Huber, C. Roitsch, J. W. Fenton 2nd, Science 1990, 249, 277-280.

[5] C. Y. Koh, M. Kazimirova, A. Trimnell, P. Takac, M. Labuda, P. A. Nuttall, R. M. Kini, J. Biol. Chem. 2007, 282, 29101-29113.

[6] C. Y. Koh, S. Kumar, M. Kazimirova, P. A. Nuttall, U. P. Radhakrishnan, S. Kim, P. Jagadeeswaran, T. Imamura, J. Mizuguchi, S. Iwanaga, K. Swaminathan, R. M. Kini, PLoS One 2011, 6, e26367.

[7] A. C. Figueiredo, D. de Sanctis, R. Gutierrez-Gallego, T. B. Cereija, S. Macedo-Ribeiro, P. Fuentes-Prior, P. J. Pereira, Proc. Natl. Acad. Sci. USA 2012, 109, 3649-3658.

[8] E. E. Watson, X. Liu, R. E. Thompson, J. Ripoll-Rozada, M. Wu, I. Alwis, A. Gori, C. T. Loh, B. L. Parker, G. Otting, S. Jackson, P. J. B. Pereira, R. J. Payne, ACS Cent. Sci. 2018, 4, 468-476.

[9] L. Pirone, J. Ripoll-Rozada, M. Leone, R. Ronca, F. Lombardo, G. Fiorentino, J. F. Andersen, P. J. B. Pereira, B. Arcà, E. Pedone, J. Biol. Chem. 2017, 292, 12632-12642.

[10] R. E. Thompson, X. Liu, J. Ripoll-Rozada, N. Alonso-Garcia, B. L. Parker, P. J. B. Pereira, R. J. Payne, Nat. Chem. 2017, 9, 909-917.

[11] E. E. Watson, J. Ripoll-Rozada, A. C. Lee, M. C. Wu, C. Franck, T. Pasch, B. Premdjee, J. Sayers, M. F. Pinto, P. M. Martins, Proc. Natl. Acad. Sci. USA 2019, 116, 13873-13878.

[12] B. M. Calisto, J. Ripoll-Rozada, L. J. Dowman, C. Franck, S. M. Agten, B. L. Parker, R. C. Veloso, N. Vale, P. Gomes, D. de. Sanctis, R. J. Payne, P. J. B. Pereira, Cell Chem. Biol. 2021, 28 , $26-33$.

[13] M. Cappello, S. Li, X. Chen, C. B. Li, L. Harrison, S. Narashimhan, C. B. Beard, S. Aksoy, Proc. Natl. Acad. Sci. USA 1998 , $95,14290-14295$.
[14] P. E. Dawson, T. W. Muir, I. Clark-Lewis, S. B. Kent, Science 1994, 266, 776-779.

[15] N. J. Mitchell, L. R. Malins, X. Liu, R. E. Thompson, B. Chan, L. Radom, R. J. Payne, J. Am. Chem. Soc. 2015, 137, 14011-14014.

[16] Q. Wan, S. J. Danishefsky, Angew. Chem. Int. Ed. 2007, 46, $9248-$ 9252; Angew. Chem. 2007, 119, 9408-9412.

[17] S. S. Kulkarni, E. E. Watson, B. Premdjee, K. W. Conde-Frieboes, R. J. Payne, Nat. Protoc. 2019, 14, 2229-2257.

[18] N. J. Mitchell, J. Sayers, S. S. Kulkarni, D. Clayton, A. M. Goldys, J. Ripoll-Rozada, P. J. B. Pereira, B. Chan, L. Radom, R. J. Payne, Chem 2017, 2, 703-715.

[19] L. S. Simpson, T. S. Widlanski, J. Am. Chem. Soc. 2006, 128, $1605-1610$.

[20] J. W. C. Maxwell, R. J. Payne, Curr. Opin. Chem. Biol. 2020, 58 , $72-85$.

[21] M. J. Stone, R. J. Payne, Acc. Chem. Res. 2015, 48, 2251-2261.

[22] R. E. Thompson, X. Liu, N. Alonso-Garcia, P. J. Pereira, K. A. Jolliffe, R. J. Payne, J. Am. Chem. Soc. 2014, 136, 8161-8164.

[23] C. Haase, H. Rohde, O. Seitz, Angew. Chem. Int. Ed. 2008, 47, 6807-6810; Angew. Chem. 2008, 120, 6912-6915.

[24] T. J. Rydel, M. Yin, K. P. Padmanabhan, D. T. Blankenship, A. D. Cardin, P. E. Correa, J. Fenton, A. Tulinsky, J. Biol. Chem. 1994, 269, 22000-22006.

[25] J. W. Williams, J. F. Morrison, Methods Enzymol. 1979, 63, 437467.

[26] H. C. Hemker, P. Giesen, R. AlDieri, V. Regnault, E. de Smed, R. Wagenvoord, T. Lecompte, S. Beguin, Pathophysiol. Haemostasis Thromb. 2002, 32, 249-253.

[27] N. Mackman, Anesth. Analg. 2009, 108, 1447-1452.

[28] J. P. Wood, P. E. Ellery, S. A. Maroney, A. E. Mast, Blood 2014, 123, 2934-2943.

[29] G. Soslau, R. Class, D. A. Morgan, C. Foster, S. T. Lord, P. Marchese, Z. M. Ruggeri, J. Biol. Chem. 2001, 276, $21173-$ 21183.

[30] P. S. Gandhi, Z. W. Chen, E. Di Cera, J. Biol. Chem. 2010, 285, $15393-15398$

[31] A. Y. Mehta, J. N. Thakkar, B. M. Mohammed, E. J. Martin, D. F. Brophy, T. Kishimoto, U. R. Desai, J. Med. Chem. 2014, 57, $3030-3039$

[32] Z. S. Kaplan, A. Zarpellon, I. Alwis, Y. Yuan, J. McFadyen, M. Ghasemzadeh, S. M. Schoenwaelder, Z. M. Ruggeri, S. P. Jackson, Nat. Commun. 2015, 6, 7835.

[33] F. A. Klok, M. Kruip, N. J. M. van der Meer, M. S. Arbous, D. Gommers, K. M. Kant, F. H. J. Kaptein, J. van Paassen, M. A. M. Stals, M. V. Huisman, H. Endeman, Thromb. Res. 2020, 191, $148-150$.

Manuscript received: November 12, 2020

Revised manuscript received: December 14, 2020

Accepted manuscript online: December 20, 2020

Version of record online: January 28, 2021 